\title{
Profile of plecanatide in the treatment of chronic idiopathic constipation: design, development, and place in therapy
}

This article was published in the following Dove Press journal: Clinical and Experimental Gastroenterology

\author{
Amol Sharma \\ Anam Asif Herekar \\ Jigar Bhagatwala \\ Satish SC Rao \\ Division of Gastroenterology and \\ Hepatology, Department of Medicine, \\ Medical College of Georgia, Augusta \\ University, Augusta, GA, USA
}

\begin{abstract}
Constipation is a multifactorial disorder that can cause significant psychological distress to patients and economic burden on the health care system. Many patients are not satisfied with their current established treatment, highlighting the need for new and improved therapeutic options. Guanylate cyclase-C (GC-C)/cyclic guanosine monophosphate agonists have emerged as a safe and efficacious class of drugs for the treatment of chronic idiopathic constipation (CIC). Plecanatide, a second-in-class, US FDA-approved, synthetic GC-C agonist, has recently been approved in the US for the treatment of irritable bowel syndrome with constipation at doses of 3 and $6 \mathrm{mg}$ and CIC at the $3 \mathrm{mg}$ dosage. In this study, we summarize the design of this novel 16-amino acid uroguanylin analog, drug development through Phase I, II, and III clinical studies, and its role in the treatment of CIC.
\end{abstract}

Keywords: plecanatide, uroguanylin, constipation

\section{Introduction}

Constipation is a major health problem both domestically and globally. The average US and global prevalence is $\sim 14 \%-15 \%$. $^{1}$ Two and a half million outpatient doctor visits are attributed to constipation each year. ${ }^{2}$ In US alone, constipation results in a significant economic burden with an estimated $\$ 821$ million spent annually on laxatives. ${ }^{3}$ Constipation severely impairs quality of life and causes significant psychological distress. ${ }^{4}$ Constipation affects females more than males, older individuals, and more people of lower socioeconomic status. ${ }^{1}$

Constipation is associated with $<3$ complete spontaneous bowel movements (CSBMs) a week. ${ }^{5}$ However, if the definition is restricted to number of bowel movements (BMs), constipation is grossly underdiagnosed, and the prevalence is underestimated. Other key historical clues associated with constipation include hard or lumpy stool character, lengthy and ineffective attempted defecation or straining, sense of incomplete evacuation of stool, bloating, and use of digital maneuvers.

After the exclusion of secondary causes, constipation can be further subclassified into dyssynergic defecation, irritable bowel syndrome, constipation-predominant (IBS-C), and chronic idiopathic constipation (CIC). According to a meta-analysis of 41 studies, CIC has a pooled prevalence of $14 \%$ (CI 12\%-17\%). ${ }^{6} \mathrm{CIC}$ is a chronic, multisymptom disorder that is associated with negative impact on workplace and school productivity. An estimated 23\% annual loss of productivity is attributed to absenteeism of a quarter of employees suffering from CIC. ${ }^{7}$ Approximately $60 \%$ of the patients with $\mathrm{CIC}$ were not satisfied by their current prescribed chronic treatment,
Correspondence: Amol Sharma

Division of Gastroenterology and Hepatology, Digestive Health Center, Medical College of Georgia, Augusta University, II 20 I5th Street, AD-2226, Augusta, GA 30912, USA

Email amosharma@augusta.edu 
highlighting the need for new and improved therapeutic options. $^{7}$

Guanylate cyclase-C (GC-C)/cyclic guanosine monophosphate (cGMP) agonists have emerged as a safe and efficacious class of drugs for the treatment of CIC. GC-C agonists not only improve stool consistency and number of BMs in subjects with CIC but also provide visceral analgesia. ${ }^{8-10}$ Plecanatide is the second-in-class GC-C agonist following linaclotide and was approved by the US FDA for the treatment of CIC ( $3 \mathrm{mg}$ ) and IBS-C (3 and $6 \mathrm{mg}$ ) in patients aged $>18$ years. Plecanatide is a 16 -amino acid peptide analog to endogenous uroguanylin, whereas linaclotide is a 14-amino acid peptide derived from Escherichia coli heatstable enterotoxin. This study aims to review the steps taken in the design and development of plecanatide and its current use in the treatment of CIC.

GC-C receptors play a critical role in a multitude of routine gastrointestinal (GI) tract functions. GC-C receptor activation maintains intestinal electrolyte and fluid homeostasis, supports the mucosal barrier, attenuates visceral pain, and inhibits inflammation. ${ }^{8-12}$ In addition, GC-C receptor modulation may have a role in the treatment of colorectal cancer. ${ }^{13}$ GC-C receptors are located on the mucosal epithelial cells throughout the entire length of the GI tract. Endogenous paracrine peptide hormones, uroguanylin and guanylin, act on these receptors in a $\mathrm{pH}$-dependent manner. Uroguanylin, a 16-amino acid peptide, acts proximally in the acidic environments ( $\mathrm{pH}$ 5-7) of duodenum and proximal jejunum through its $\mathrm{N}$-terminal $\mathrm{pH}$-sensing aspartate and glutamate residues. In contrast, guanylin, a 15 -amino acid peptide, is most potent in the neutral to slightly basic environment of the colorectum. ${ }^{14,15}$ Activation of the GC-C receptor results in a cascade of events, starting with the conversion of GTP into cGMP. cGMP activates a series of mediators that stimulate cystic fibrosis transmembrane conductance regulator channels, resulting in the release of $\mathrm{Cl}^{-}$and $\mathrm{HCO}_{3}^{-}$ions that osmotically draw the water into the intestinal lumen. It also blocks the $\mathrm{Na}^{+} / \mathrm{H}^{+}$exchanger-3, allowing $\mathrm{Na}^{+}$to remain in the lumen, as shown in Figure 1. Increased luminal water content helps facilitate BMs by softening the stool.

Plecanatide (Synergy Pharmaceuticals, New York, NY, USA) shares the same structural features of uroguanylin, differing only in the substitution of aspartate with glutamate at the third position in N-terminus. Plecanatide has been shown to be eight times more potent than its endogenous counterpart. ${ }^{16}$ This makes plecanatide a promising therapeutic agent for alleviating constipation and providing visceral analgesia in CIC and IBS-C.

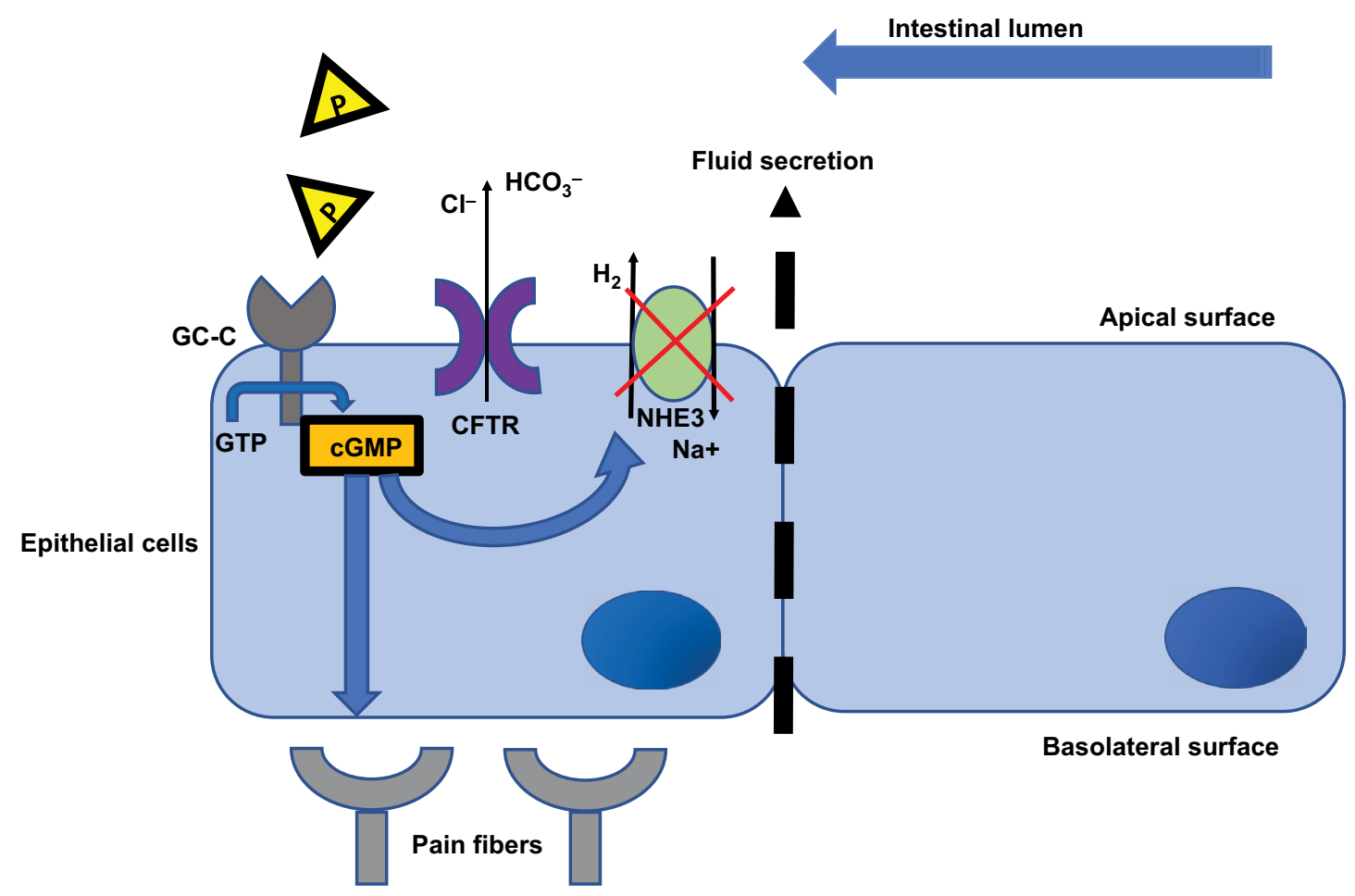

Figure I Mechanistic action of plecanatide (P, yellow triangles) in the GI tract.

Abbreviations: CFTR, cystic fibrosis transmembrane conductance regulator; cGMP, cyclic guanosine monophosphate; GC-C, guanylate cyclase-C receptor; GI, gastrointestinal; NHE3, sodium hydrogen exchanger-3. 


\section{Phase I study: drug safety}

In the first in-human placebo-controlled trial conducted on a cohort of healthy volunteers, 71 subjects were administered oral doses of plecanatide up to $48.6 \mathrm{mg}$ to assess its safety and tolerability. ${ }^{17}$ Diarrhea of mild-to-moderate intensity was the most common adverse event seen in both drug and placebo arms (24.5\% vs $22.2 \%)$. However, dose-limiting toxicity was due to abdominal pain and nausea seen in the two highest dosages of 24.3 and $48.6 \mathrm{mg}$.

Pharmacodynamic assessments were made by assessing the time-to-first BM, stool frequency, and consistency assessed by Bristol Stool Form Scale (BSFS) over a 48-hour period. With the exception of $5.1 \mathrm{mg}$ cohort, all doses resulted in first BM within 24 hours. Blood samples collected up to 48 hours demonstrated no detectable plasma concentration of drug. Mean BSFS scores plateau between doses of 5.4 and $8.1 \mathrm{mg}$. Plecanatide doses between 0.3 and $9 \mathrm{mg}$ were selected for the Phase IIa study.

\section{Phase II studies: drug efficacy}

Eighty CIC subjects were enrolled in a dose-ranging Phase IIa study evaluating plecanatide doses of $0.3,1,3$, and $9 \mathrm{mg}$ vs placebo to assess the pharmacokinetic and pharmacodynamic profiles. ${ }^{18}$ Reported adverse event rate with the study drug was $17.2 \%$ compared to $10 \%$ in placebo. None of the subjects in the study drug arm reported bothersome diarrhea. A decrease in time-to-first BM was noted with all doses of plecanatide compared to placebo. Subjects also showed improvement in abdominal discomfort, straining, stool consistency, and frequency.

Nine hundred fifty-one subjects ( $86.5 \%$ females) meeting the modified Rome III criteria and demonstrating $<3$ CSBMs per week were enrolled into a 12-week, double-blinded, multi-center clinical trial randomized to receive three doses of plecanatide $(0.3,1$, or $3 \mathrm{mg})$ or placebo. ${ }^{19}$ The FDA-approved composite primary efficacy end point defined a responder as a weekly improvement in 9 out of total 12 weeks, including 3 of the last 4 weeks. A weekly responder was defined as a subject who had $>3$ CSBMs per week and an improvement of 1 CSBM per week from baseline. CIC subjects receiving $3 \mathrm{mg}$ showed a significantly higher overall response rate compared to placebo ( $21.5 \%$ vs $11.5 \%$, respectively; $P=0.003$ ). The $3 \mathrm{mg}$ dose of plecanatide was also proven to be significantly better than placebo in achieving all secondary end points - stool consistency, straining, CIC severity, frequency of CSBMs and spontaneous bowel movements (SBMs), and Patient Assessment of Constipation Symptoms and Quality of Life. However, it is important to note that since normal consistency of stool is different in both men and women according to a recently published study in a large cohort of US population, bowel consistency goals will also differ among the two genders. ${ }^{20}$

\section{Phase III studies: double-blinded randomized controlled trials}

Two separate large plecanatide Phase III studies in over 1,300 CIC subjects each (CIC3 and National CIC3) compared treatment arms of 3 and $6 \mathrm{mg}$ once daily to placebo over a 12-week period of treatment. ${ }^{21,22}$ Both followed similar clinical trial design with the same FDA-approved composite primary end point. Inclusion criteria consisted of male or female patients from 18 to 80 years with a body mass index of $18-40 \mathrm{~kg} / \mathrm{m}^{2}$ with CIC meeting the modified Rome III criteria. In the CIC3 study (intention-to-treat [ITT] population $=1,337$ ), both doses of plecanatide showed a significantly higher percentage of responders compared to placebo ( $3 \mathrm{mg}$ $=20.1 \%$; $6 \mathrm{mg}=20.0 \%$; placebo $=12.8 \%, P=0.004$ for both comparisons). Similarly, in the National CIC3 study (ITT population $=1,346$ ), both plecanatide doses showed a significantly higher overall response rate $(3 \mathrm{mg}=21.0 \%$; $6 \mathrm{mg}$ $=19.5 \%$; and placebo $=10.2 \%, P<0.001)$. Secondary end points such as straining, bloating, treatment satisfaction, and desire to continue treatment were also superior to placebo.

Diarrhea was the most common adverse event, occurring in $3.2 \%$ of the subjects in the $3 \mathrm{mg}$ plecanatide arm and $4.5 \%$ in the $6 \mathrm{mg}$ arm compared to $1.3 \%$ in the placebo in the CIC 3 study. Similar rates of diarrhea occurred in the National CIC3 study with $5.9 \%$ in the $3 \mathrm{mg}$ arm and $5.7 \%$ in the $6 \mathrm{mg}$ arm compared to $1.3 \%$ in the placebo arm. Plecanatide was well tolerated with low rates of discontinuation due to side effects.

To evaluate the long-term efficacy and safety of plecanatide, an open-label study was conducted over a period of 72 weeks. ${ }^{23}$ The most common side effects noted were diarrhea $(7.1 \%)$, leading to discontinuation in $3.1 \%$ and urinary tract infection in $2.2 \%$. No changes of any clinical relevance were noted in vital signs, electrocardiogram, and clinical laboratory tests.

\section{Role of plecanatide in the treatment of $\mathrm{CIC}$}

Initial management of CIC without alarm features, such as unintentional weight loss, unexplained iron deficiency anemia, and rectal bleeding, consists of dietary and lifestyle modifications. Such modifications entail as increasing fluid and fiber intake, dietary changes, and exercise. Fiber can treat constipation through bulking stool, as a nonabsorbable, complex carbohydrate drawing fluid from the colon, or 
undergoing partial fermentation and malabsorption, accelerating colonic transit. Treatment of mild-to-moderate chronic constipation with fiber is supported by a Grade B recommendation with level II (fair) evidence. ${ }^{24}$ Particularly, mixed soluble/insoluble fiber supplements, such as psyllium, prunes, and Suprafiber, would be more tolerable and associated with less bloating than purely insoluble fiber supplementation. ${ }^{25-28}$

Osmotic laxatives, such as lactulose, polyethylene glycol, or magnesium-containing preparations, are safe and effective treatment options for CIC patients who do not respond to dietary and lifestyle modifications (Figure 2). Stimulant laxatives, such as bisacodyl, senna, and sodium picosulfate, stimulate peristaltic action of the colon in addition to altering water and electrolyte secretion. Prolonged use of stimulant laxatives for $>1$ year has shown to result in the loss of haustral fold in greater than a quarter of patients and may lead to drug-dependent constipation. ${ }^{29}$ Therefore, for severe constipation, stimulant laxatives should be reserved for rescue therapy.

Laxative-refractory constipation for $>6$ months should be referred for further evaluation with appropriate neurophysiological testing at an expert academic medical center. Once medically refractory conditions, such as dyssynergic defecation, Hirschsprung's disease, and colonic neuropathy have been excluded and/or addressed, GC-C agonists should be considered first-line treatment for laxative-refractory $\mathrm{CIC}$ due to their excellent efficacy and safety profile. Linaclotide with its action on the entire GI tract is hypothesized to be associated with higher incidences of diarrhea compared to plecanatide, which is $\mathrm{pH}$ dependent and affects only the proximal portion of the small bowel. ${ }^{10}$ However, in a rigorous meta-analysis that standardized the definition of diarrhea and compared clinical trial data between the two GC-C agonists, linaclotide and plecanatide, there was no difference in efficacy or adverse event rates, including diarrhea. ${ }^{30}$ In the absence of strong clinical evidence, the use of either GC-C agonist, linaclotide or plecanatide, as a first-line agent for laxative-refractory constipation would be reasonable. Lubiprostone, a bicyclic fatty acid derived from prostaglandin E1 that activates CIC-2 chloride channels, should be considered a second-line pro-secretory agent for laxative-refractory CIC. While an effective treatment for CIC, ${ }^{31}$ lubiprostone is associated with significantly more adverse events with an RR of $1.79 .^{32}$ Its most common adverse effects include nausea $(19.8 \%)$, diarrhea $(9.7 \%)$, and headache $(6.9 \%) .{ }^{33}$

Two other potential classes of medications, serotonergic prokinetic agents and ileal bile acid transporters (IBATs), may also provide further options for laxative-refractory CIC patients in the future. Currently, medications in these classes are not FDA-approved for use in the USA. Enterochromaffin cells distributed throughout the GI tract produce large amounts of serotonin or 5-hydroxytryptamine (5-HT)

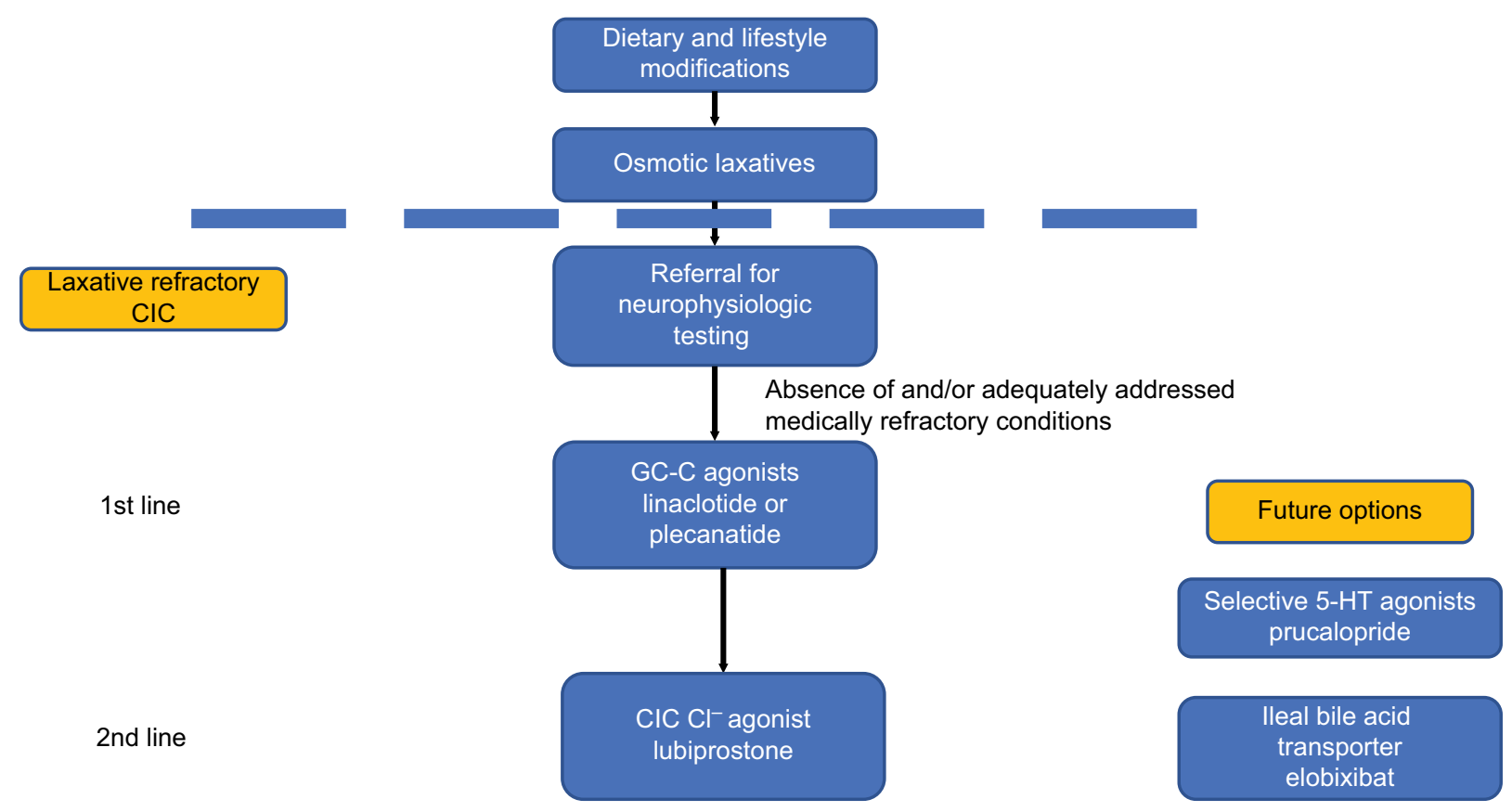

Figure 2 Proposed treatment for $\mathrm{ClC}$ and place in therapy of plecanatide.

Abbreviations: $\mathrm{CIC}$, chronic idiopathic constipation; $\mathrm{Cl}^{-}$, chloride; GC-C, guanylate cyclase-C; 5- $\mathrm{HT}$, 5-hydroxytryptamine. 
that modulates visceral sensation and motility. Increased selectivity for 5-HT3 and 5-HT4 receptors in the GI tract has allowed newer generation 5-HT agonists, such as prucalopride, velusetrag, naronapride, and mosapride, to avoid adverse cardiac arrhythmias and ischemic events associated with their predecessors, cisapride, and tegaserod that were withdrawn from the market. Of these agents, prucalopride has been studied in placebo-controlled eight clinical trials with proven efficacy over placebo. ${ }^{32}$ IBATs reduce the ileal reabsorption of bile acids, resulting in the increased concentration of colonic bile acid concentration, which stimulates colonic secretion and motility. Randomized placebo-controlled Phase IIb trials of elobixibat, a firstgeneration IBAT, showed significantly improved number of SBMs per week in doses ranging from 5 to $15 \mathrm{mg}$. Recently, elobixibat was approved for use in Japan after promising Phase III clinical trial results.

\section{Conclusion}

Plecanatide, an endogenous uroguanylin analog and GC-C agonist, is an effective treatment option for patients suffering from CIC. Its lack of systemic absorption helps to avoid systemic adverse effects and drug-drug interactions, providing plecanatide with an excellent safety profile. Despite its $\mathrm{pH}$-dependent action predominantly in the proximal small bowel, plecanatide has similar rates of its predominant adverse event of diarrhea to linaclotide, the first-to-market GC-C agonist. Therefore, plecanatide or linaclotide may be considered first-line agents for the treatment of laxativerefractory CIC in the absence of or adequately addressed medically refractory conditions. Future therapeutic options for CIC patients include serotonergic or 5-HT promotility agents and IBATs.

\section{Acknowledgment}

The authors thank Ms. Helen Smith and Kimberly Donaldson for secretarial support.

\section{Author contributions}

AS contributed to manuscript concept and design, critical revision, and final approval; AAH contributed to manuscript preparation; JB contributed to manuscript preparation; and SSCR contributed to manuscript concept and design, critical revision, and final approval. All authors contributed to data analysis, drafting and revising the article, gave final approval of the version to be published, and agree to be accountable for all aspects of the work.

\section{Disclosure}

AS has served as an advisory board member for Ironwood and Synergy Pharmaceuticals. SSCR has served as an advisory board member and received research grant support from Forest Laboratories, Ironwood Pharmaceuticals, and Synergy Pharmaceuticals. The authors report no other conflicts of interest in this work.

\section{References}

1. Higgins PD, Johanson JF. Epidemiology of constipation in North America: a systematic review. Am J Gastroenterol. 2004;99(4):750-759.

2. Sonnenberg A, Koch TR. Physician visits in the United States for constipation: 1958 to 1986. Dig Dis Sci. 1989;34(4):606-611.

3. Rao SS. Constipation: evaluation and treatment of colonic and anorectal motility disorders. Gastroenterol Clin North Am. 2007;36(3):687-711.

4. Rao SS, Seaton K, Miller MJ, et al. Psychological profiles and quality of life differ between patients with dyssynergia and those with slow transit constipation. J Psychosom Res. 2007;63(4):441-449.

5. Suares NC, Ford AC. Systematic review: the effects of fibre in the management of chronic idiopathic constipation. Aliment Pharmacol Ther. 2011;33(8):895-901.

6. Bharucha AE, Dorn SD, Lembo A, Pressman A. American Gastroenterological Association medical position statement on constipation. Gastroenterology. 2013;144(1):211-217.

7. Harris LA, Horn J, Kissous-Hunt M, Magnus L, Quigley EMM. The better understanding and recognition of the disconnects, experiences, and needs of patients with chronic idiopathic constipation (BURDEN-CIC) study: results of an online questionnaire. Adv Ther 2017;34(12):2661-2673.

8. Castro J, Harrington AM, Hughes PA, et al. Linaclotide inhibits colonic nociceptors and relieves abdominal pain via guanylate cyclase-C and extracellular cyclic guanosine 3',5'-monophosphate. Gastroenterology. 2013;145(6):1334-1346.e1-11.

9. Silos-Santiago I, Hannig G, Eutamene H, et al. Gastrointestinal pain: unraveling a novel endogenous pathway through uroguanylin/guanylate cyclase-C/cGMP activation. Pain. 2013;154(9):1820-1830.

10. Waldman SA, Camilleri M. Guanylate cyclase-C as a therapeutic target in gastrointestinal disorders. Gut. 2018;67(8):1543-1552.

11. Steinbrecher KA, Harmel-Laws E, Garin-Laflam MP, et al. Murine guanylate cyclase $\mathrm{C}$ regulates colonic injury and inflammation. J Immunol. 2011;186(12):7205-7214.

12. Han X, Mann E, Gilbert S, et al. Loss of guanylyl cyclase C (GCC) signaling leads to dysfunctional intestinal barrier. PLoS One. 2011;6(1):e16139.

13. Shailubhai K, Yu HH, Karunanandaa K, et al. Uroguanylin treatment suppresses polyp formation in the $\operatorname{Apc}(\mathrm{Min} /+)$ mouse and induces apoptosis in human colon adenocarcinoma cells via cyclic GMP. Cancer Res. 2000;60(18):5151-5157.

14. Qian X, Prabhakar S, Nandi A, Visweswariah SS, Goy MF. Expression of GC-C, a receptor-guanylate cyclase, and its endogenous ligands uroguanylin and guanylin along the rostrocaudal axis of the intestine. Endocrinology. 2000;141(9):3210-3224.

15. Hamra FK, Eber SL, Chin DT, Currie MG, Forte LR. Regulation of intestinal uroguanylin/guanylin receptor-mediated responses by mucosal acidity. Proc Natl Acad Sci U S A. 1997;94(6):2705-2710.

16. Shailubhai K, Palejwala V, Arjunan KP, et al. Plecanatide and dolcanatide, novel guanylate cyclase-C agonists, ameliorate gastrointestinal inflammation in experimental models of murine colitis. World $J$ Gastrointest Pharmacol Ther. 2015;6(4):213-222.

17. Shailubhai K, Comiskey S, Foss JA, et al. Plecanatide, an oral guanylate cyclase $\mathrm{C}$ agonist acting locally in the gastrointestinal tract, is safe and well-tolerated in single doses. Dig Dis Sci. 2013;58(9):2580-2586. 
18. Shailubhai, K, Talluto, C, Comiskey, S. A phase IIa randomized, double blind, placebo-controlled, 14-day repeat, oral, range-finding study to assess the safety, pharmacokinetic and pharmacodynamic effects of plecanatide (SP-304) in patients with chronic idiopathic constipation (Protocol No. SP-SP304201-09). Poster presented at: Digestive Disease Week (DDW); 2010; New Orleans, LA.

19. Miner PB, Surowitz R, Fogel R, et al. 925g Plecanatide, a novel guanylate cyclase-C (GC-C) receptor agonist, is efficacious and safe in patients with chronic idiopathic constipation (CIC): results from a 951 patient, 12 week, multi-center trial. Gastroenterology. 2013;144(5):S163.

20. Mitsuhashi S, Ballou S, Jiang ZG, et al. Characterizing normal bowel frequency and consistency in a representative sample of adults in the United States (NHANES). Am J Gastroenterol. 2018;113(1):115-123.

21. Demicco M, Barrow L, Hickey B, Shailubhai K, Griffin P. Randomized clinical trial: efficacy and safety of plecanatide in the treatment of chronic idiopathic constipation. Therap Adv Gastroenterol. 2017;10(11):837-851.

22. Miner PB, Koltun WD, Wiener GJ, et al. A randomized phase III clinical trial of plecanatide, a uroguanylin analog, in patients with chronic idiopathic constipation. Am J Gastroenterol. 2017;112(4):613-621.

23. Barish CF, Griffin P. Safety and tolerability of plecanatide in patients with chronic idiopathic constipation: long-term evidence from an openlabel study. Curr Med Res Opin. 2018;34(4):751-755.

24. Rao SS, Yu S, Fedewa A. Systematic review: dietary fibre and FODMAP-restricted diet in the management of constipation and irritable bowel syndrome. Aliment Pharmacol Ther. 2015;41(12):1256-1270.

25. Ashraf W, Park F, Lof J, Quigley EM. Effects of psyllium therapy on stool characteristics, colon transit and anorectal function in chronic idiopathic constipation. Aliment Pharmacol Ther. 1995;9(6):639-647.
26. Cheskin LJ, Kamal N. Cr4well MD, Schuster MM, Whitehead WE. Mechanisms of constipation in older persons and effects of fiber compared with placebo. J Am Geriatr Soc. 1995;43(6):666-669.

27. Attaluri A, Donahoe R, Valestin J, Brown K, Rao SS. Randomised clinical trial: dried plums (prunes) vs. psyllium for constipation. Aliment Pharmacol Ther. 2011;33(7):822-828.

28. Erdogan A, Rao SS, Thiruvaiyaru D, et al. Randomised clinical trial: mixed soluble/insoluble fibre vs. psyllium for chronic constipation. Aliment Pharmacol Ther. 2016;44(1):35-44.

29. Joo JS, Ehrenpreis ED, Gonzalez L, et al. Alterations in colonic anatomy induced by chronic stimulant laxatives: the cathartic colon revisited. J Clin Gastroenterol. 1998;26(4):283-286.

30. Shah ED, Kim HM, Schoenfeld P. Efficacy and tolerability of guanylate cyclase-C agonists for irritable bowel syndrome with constipation and chronic idiopathic constipation: a systematic review and meta-analysis. Am J Gastroenterol. 2018;113(3):329-338.

31. Johanson JF, Morton D, Geenen J, Ueno R. Multicenter, 4-week, double-blind, randomized, placebo-controlled trial of lubiprostone, a locally-acting type- 2 chloride channel activator, in patients with chronic constipation. Am J Gastroenterol. 2008;103(1):170-177.

32. Ford AC, Moayyedi P, Lacy BE, et al. Task Force on the Management of Functional Bowel Disorders. American College of Gastroenterology monograph on the management of irritable bowel syndrome and chronic idiopathic constipation. Am J Gastroenterol. 2014;109(Suppl 1):S2-S26.

33. Lembo AJ, Johanson JF, Parkman HP, Rao SS, Miner PB, Ueno R. Long-term safety and effectiveness of lubiprostone, a chloride channel (ClC-2) activator, in patients with chronic idiopathic constipation. Dig Dis Sci. 2011;56(9):2639-2645.
Clinical and Experimental Gastroenterology

\section{Publish your work in this journal}

Clinical and Experimental Gastroenterology is an international, peerreviewed, open access, online journal publishing original research, reports, editorials, reviews and commentaries on all aspects of gastroenterology in the clinic and laboratory. This journal is included on PubMed. The manuscript management system is completely online

\section{Dovepress}

and includes a very quick and fair peer-review system, which is all easy to use. Visit http://www.dovepress.com/testimonials.php to read real quotes from published authors. 